\title{
أبو العلاء المعري والتفكير الفلسفي في لزومياته
}

\author{
إعلداد \\ أ/ ناديه بنت حســـ ضيف الله الصاعدي \\ محاضر بجامعة الباحة كلية العلوم والآداب بالمخواه
}

مجلة بحوث التربية النوعية - جامعة المنصورة

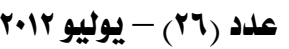




\section{أبو العلاء المعري والتفكير الفلسفي في لزوهياته}

إعداد

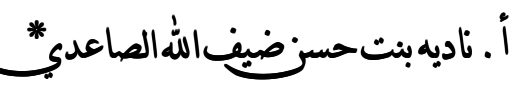

$$
\begin{aligned}
& \text { بسم الله الرحمن الرحيم } \\
& \text { الحمد لله رب العالمين والصلاة والسلام على أشرف الأنبياء والمرسلين } \\
& \text { وبعد... }
\end{aligned}
$$

فقد تميز العصر العباسي بنقلة حضارية كبرى كانت نتيجـة اتصال العرب بغيرهمه مـن

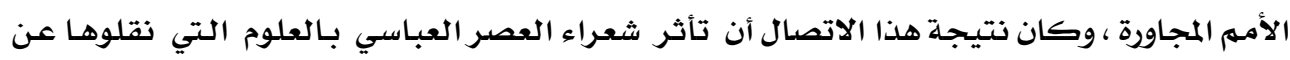

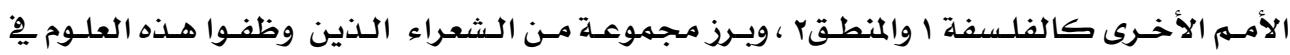
شعرهم ،وحملوا لواء التجديد مع المحافظة على القديم أمثال أبي تمام والمتنبي والمعري.

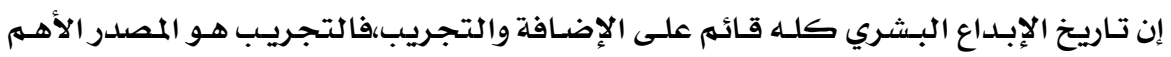

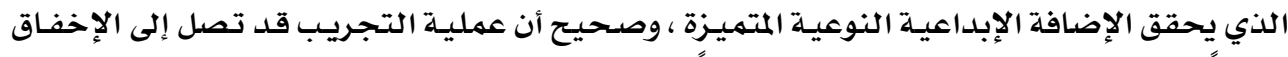

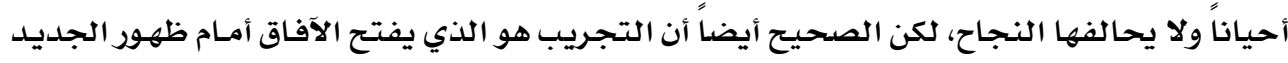

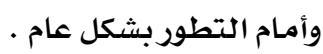

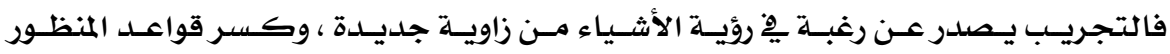

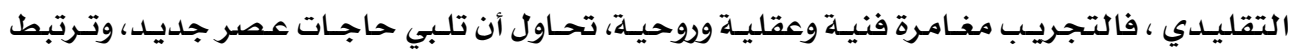

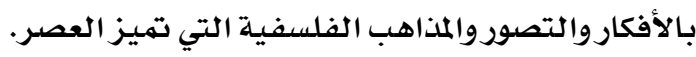

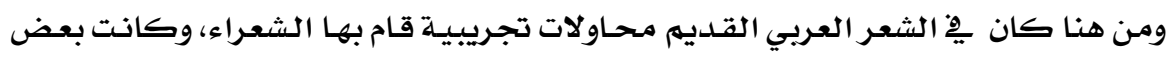

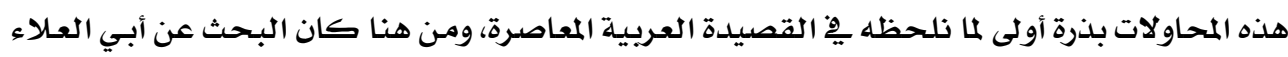

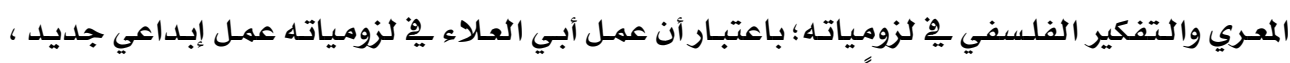

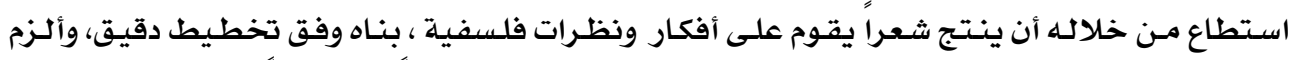

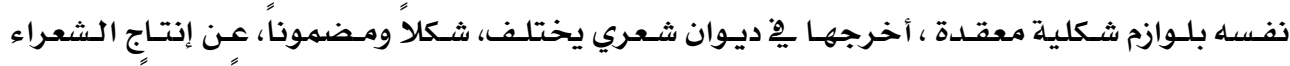
المحاصرين والسابقين له، إذ مرت حياه المعري بمرحلتين اختلف فيهما شعره اختلافاً كبيرا:

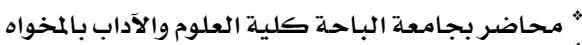

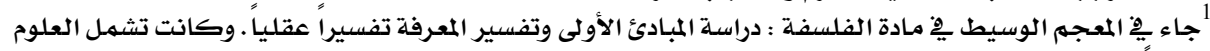

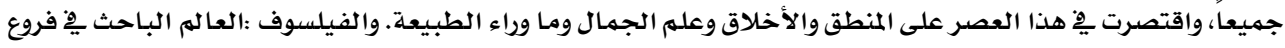

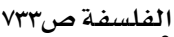

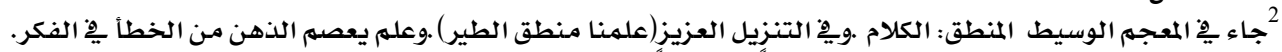

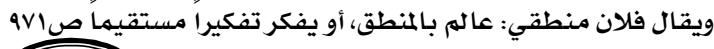


ا ـ مـرحلة مـا قبـل العزلـة ويمثلهها ديوانـه (سقط الزند) ، ويشمل الموضـوعات التقليديـة مـن مـدح

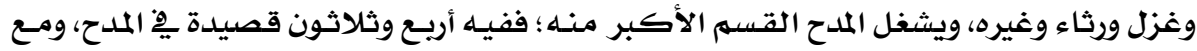

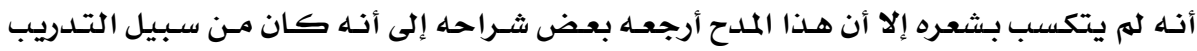

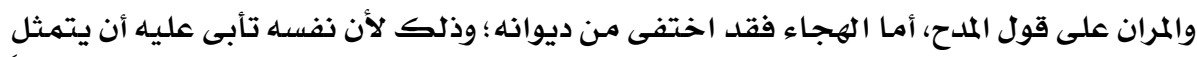

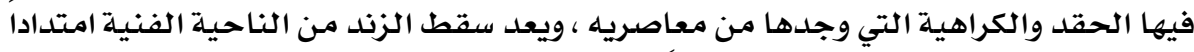

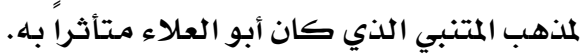

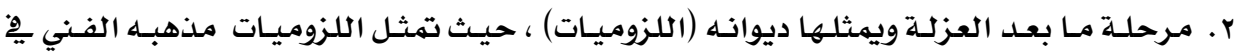

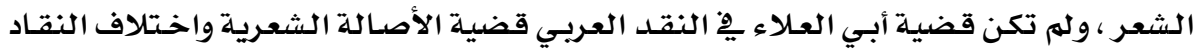

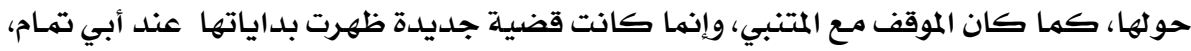

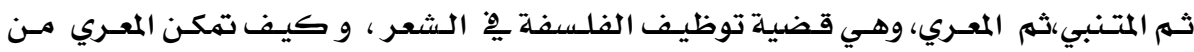

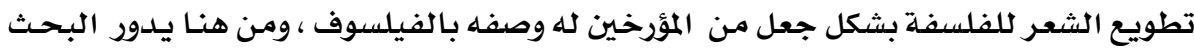

$$
\text { حول عدة إشكالات أبرزها : }
$$

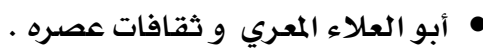

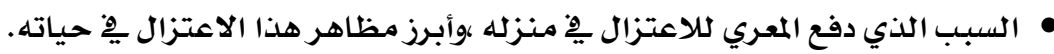

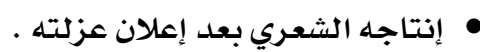

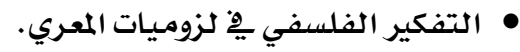

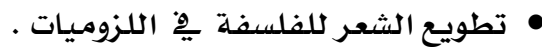

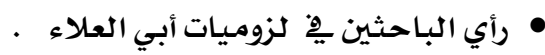

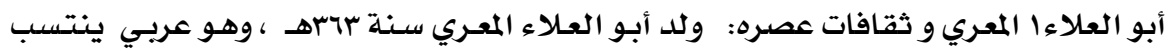

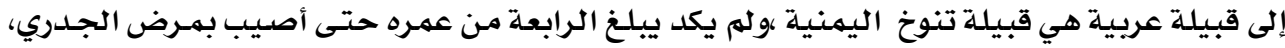

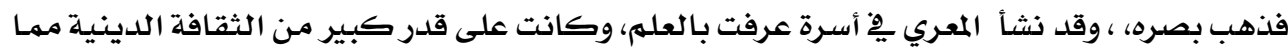

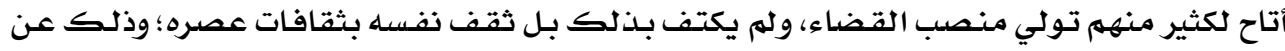

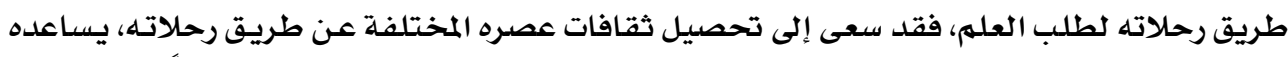

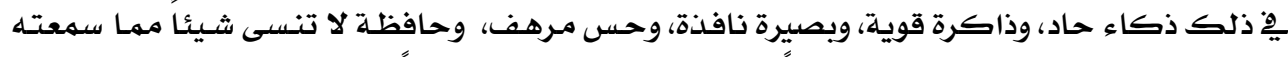

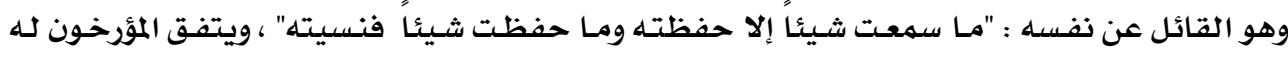

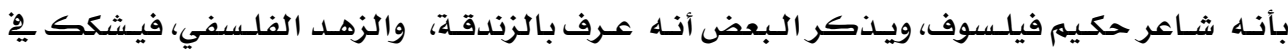
صحة إسـامسه.

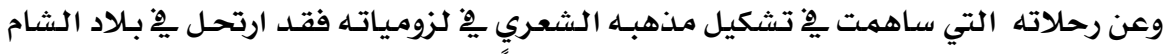

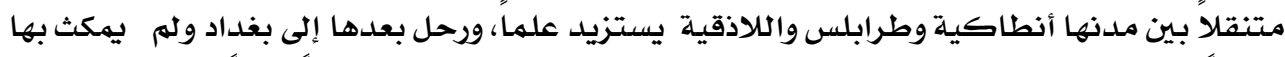

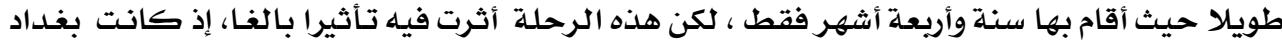


مركزاً للعلهم والعلمـاء ، بـالإضـافة إلى المذاهب الدينيـة والفلسفية ، فتمكن مـن إتقـان العربيـة والمواد

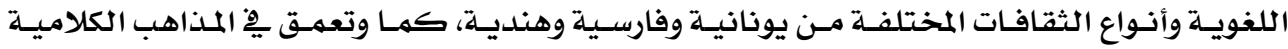

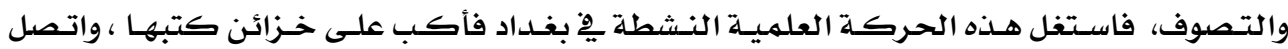

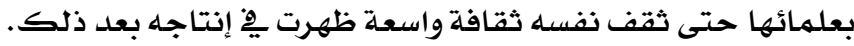

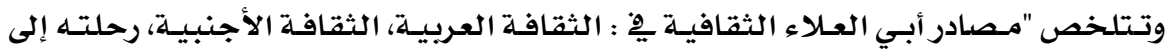

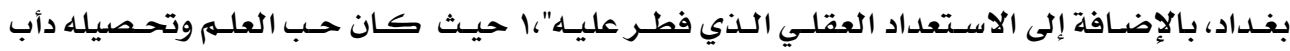

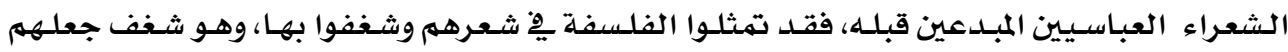

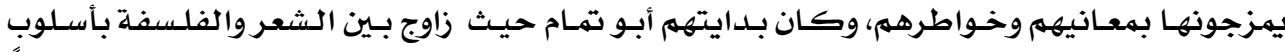

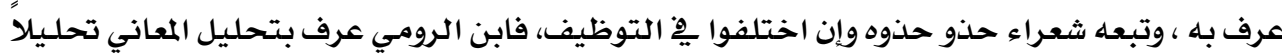

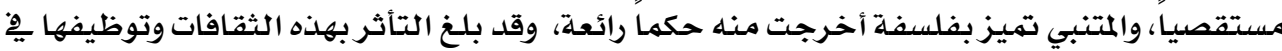

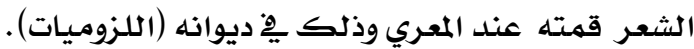

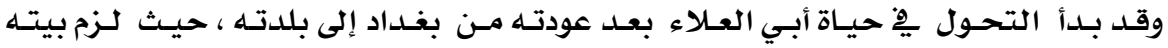

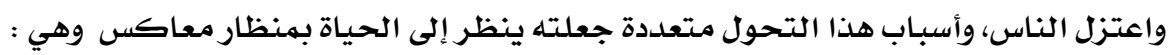

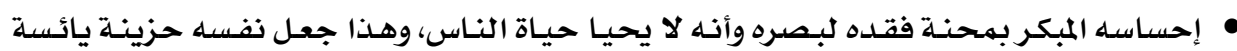

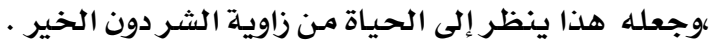

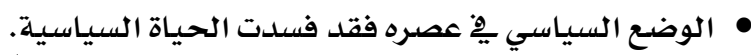

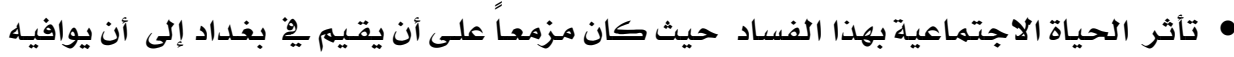

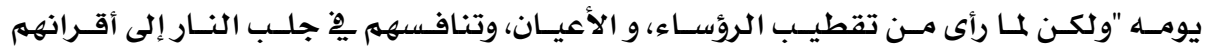

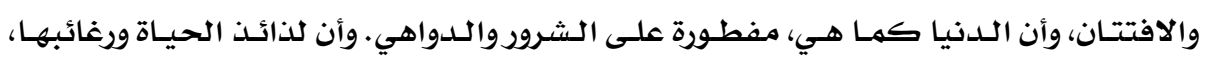

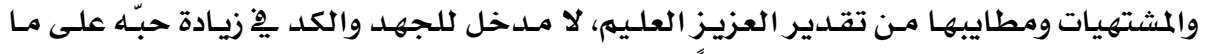

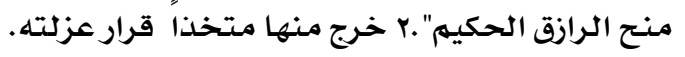

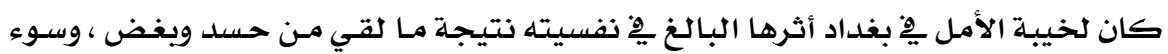

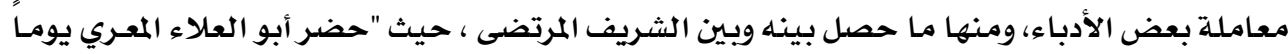

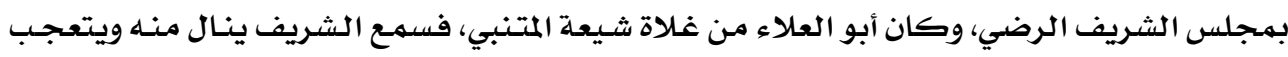

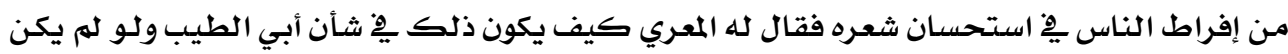
لكه إلا القصيدة التي أولها:

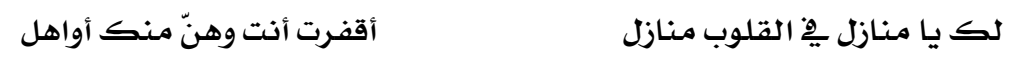

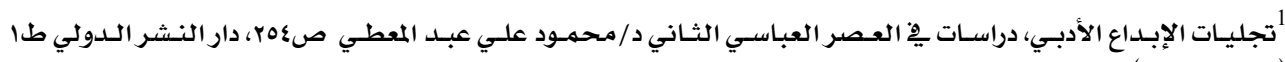

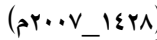

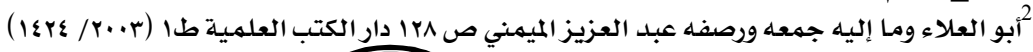


لنـا بها السبق واسـتحق التقـديه، فعجـب الشـريف لاختيـار المعـري لهـذه القـصيدة مـع إنها

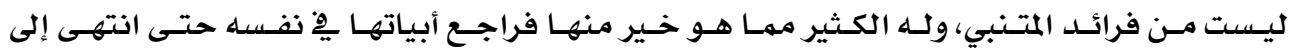

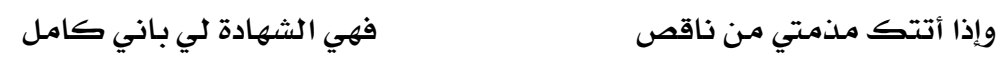

ففطن لما أراد المعري. ويقال: إنه أهانه لـذلك"' . حيث أمـر المرتضى بسحب المعـري مـن رجلـه

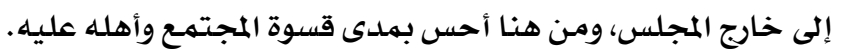

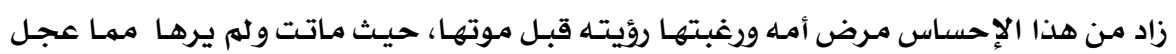

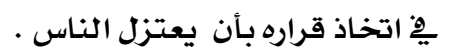
ولهذه الأسباب مجتمعة نظر المعري إلى الحياة نظرة تشاؤم، وزهد ِِّ ملذاتها،ورأى أنها

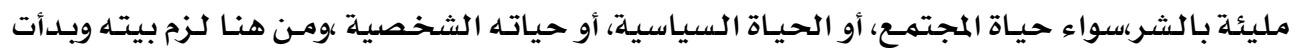

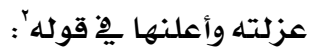

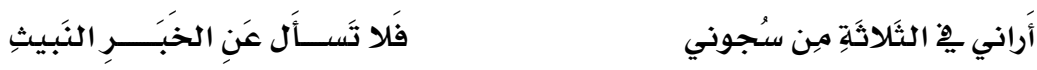

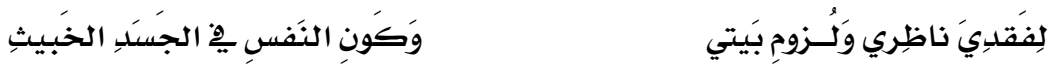

وقـد علق د / شـوقي ضـيف على هـذين البيـتين بقولـه: " سـجون ثلاثـة أحساط بهـا أبـو العـلاء

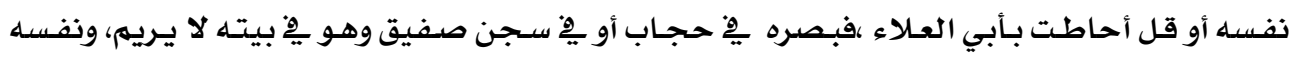

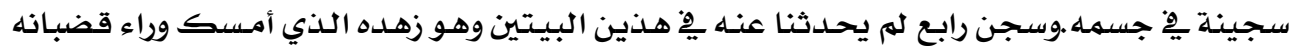

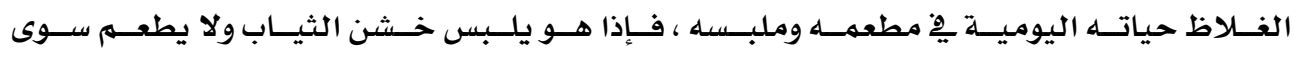
العدس والتين". الغين

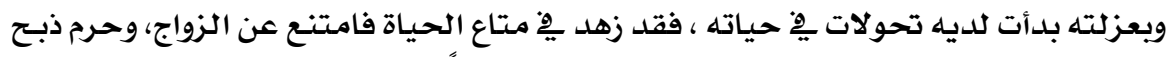

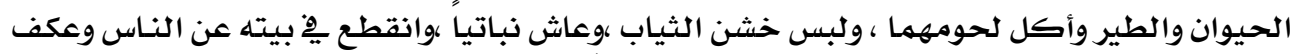

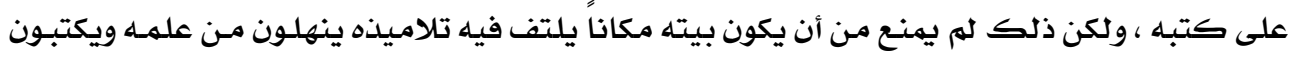

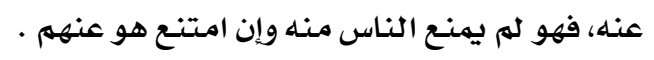

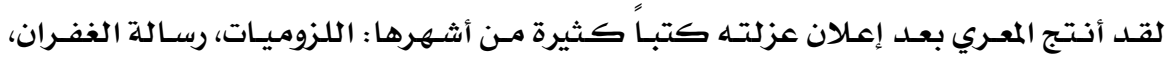

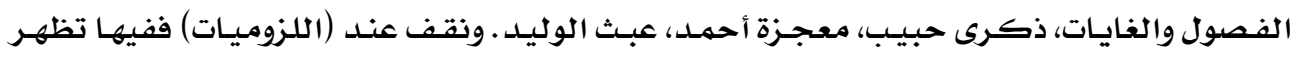

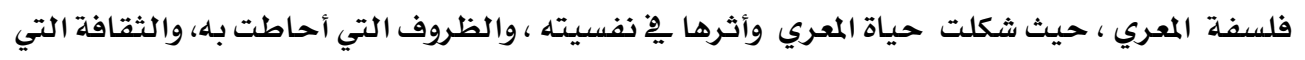

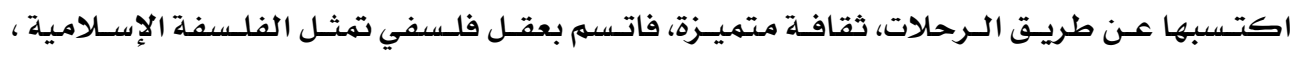

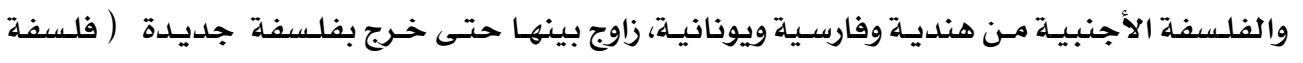

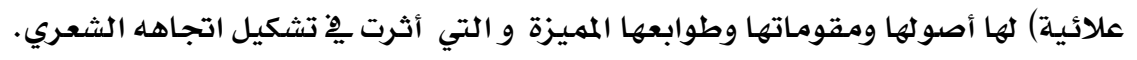

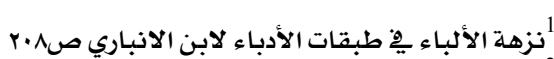

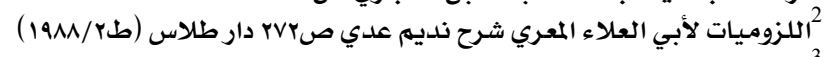

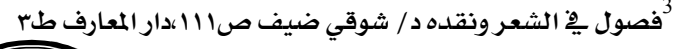


لقد أطلق أبو العلاء المعري على ديوانه الـذي كتبـه يِّ عزلتهه (لزوم مـا لا يلـزم)، ويعـد بهـذا

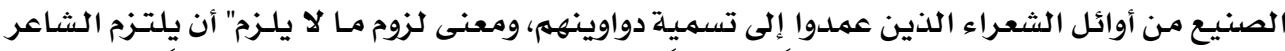

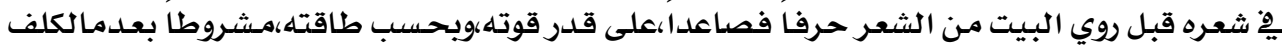

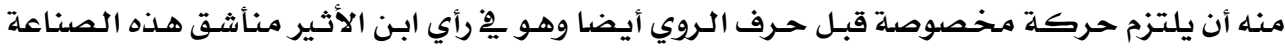

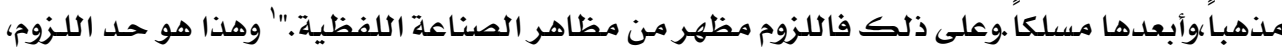

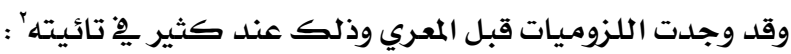

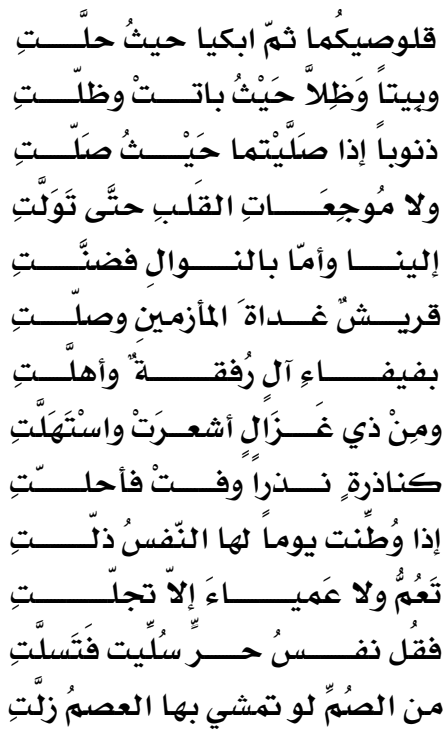

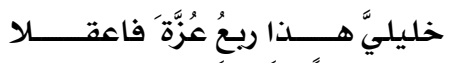

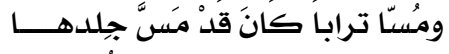

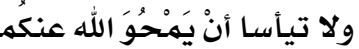

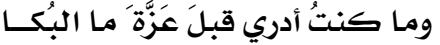

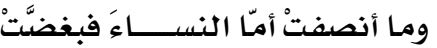

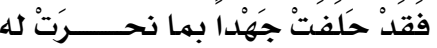

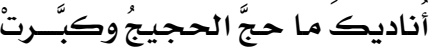

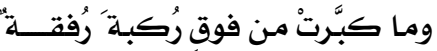

$$
\begin{aligned}
& \text { وكانت لقطع الحبل بيني وبينهـ }
\end{aligned}
$$

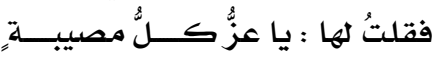

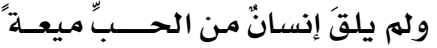

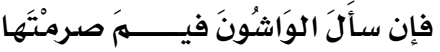

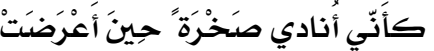

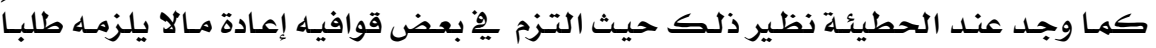

$$
\begin{aligned}
& \text { يُقَطِّعُ طُولَ الليلب الزَّفَْـــراتِ } \\
& \text { كواطبِهُا كـالجِزْع مُنْحَدِرَاتِ } \\
& \text { إذا انتبـذ العزّراب يِّ الحجَســرات } \\
& \text { مما جيرُ مـثل الآتّن النَّجِـــــرات }
\end{aligned}
$$

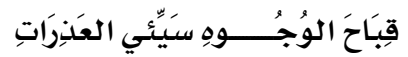

$$
\begin{aligned}
& \text { و لاتنحرون النّيب ِِِ الجحـراتِ }
\end{aligned}
$$

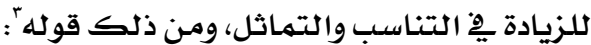

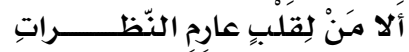

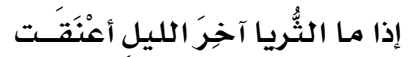

$$
\begin{aligned}
& \text { هنالك لا أخشى مقالية قائــلـل }
\end{aligned}
$$

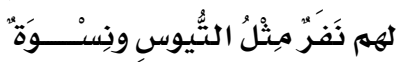

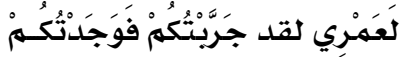

$$
\begin{aligned}
& \text { وجدتكمُ لهم تجبُروا عظم معــرمٍ }
\end{aligned}
$$

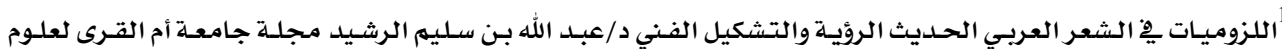

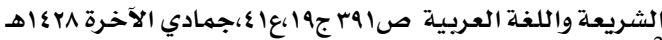

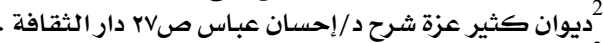

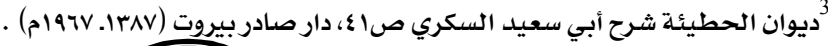


و لا أوتكمْ مـالي على العثـرات

مهاريسُ ترعى عازب القَفَراتِ

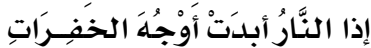

يُبَاكِرْنَ بَرَدْ الماءٍِ ِِِِ السَّبَرَات

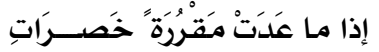

فإن يصطنعني الله لا أصطنعكـهُ عطائُ إلهي إذ بخلتـــــم بهـالكـــم

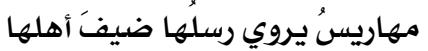

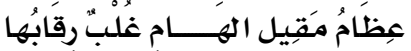

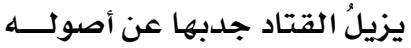

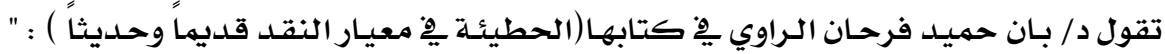

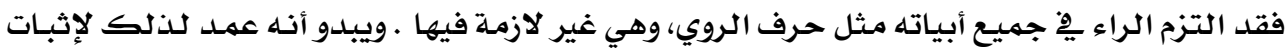

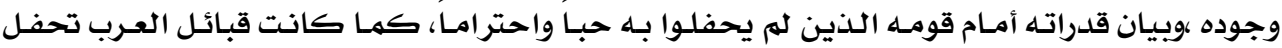
بالشعراء من أبنائها وتتفاخر بهره."'

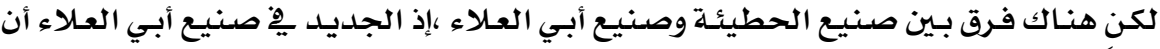

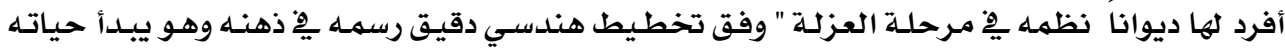

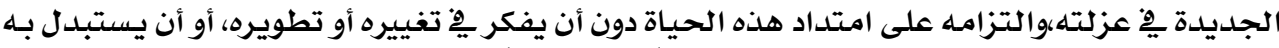

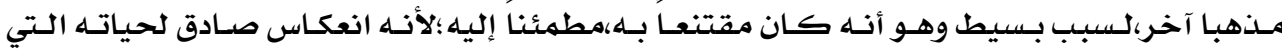

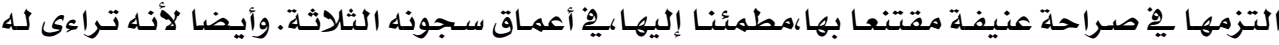

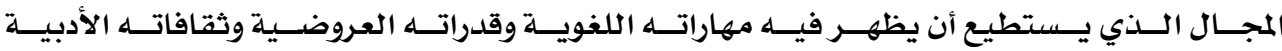

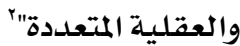

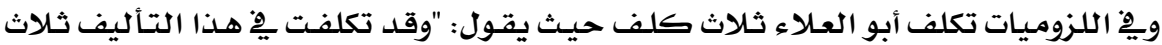
كلف،الأولى:أن ينتظم حروف المعجم عن آخرها، والثانية: أن يجيء رويه بالحركات الثرات الثلاث وبالسكون

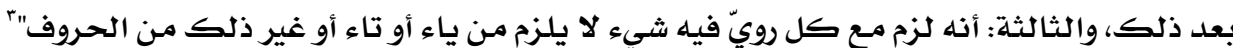
إن أسـاس التفكير الفلسفي لأبي العلاء ينطلق من عدة أمور هي: حياته الشخصيـة ، تشاؤمـه،

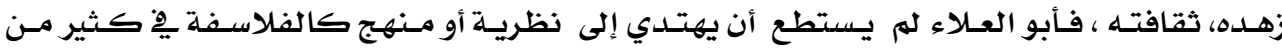
المسـائل والمشكلات فشك واتسـع عليـه الشك، وهـذا ظـاهر يْ لزومياتـه حيـث تـدور اللزوميـات حـول

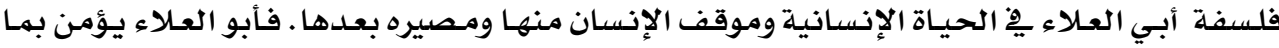

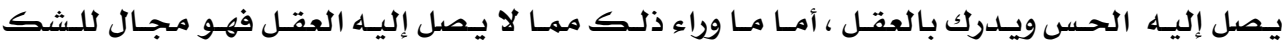

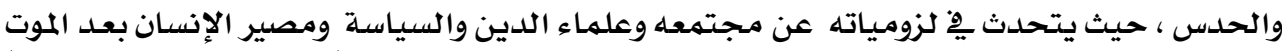
والروح واليوم الآخر وغيرها ، ويعالج هذه الموضوعات معالجة تكثف أحيانا عن يقين صـادق ، وأحيانا 


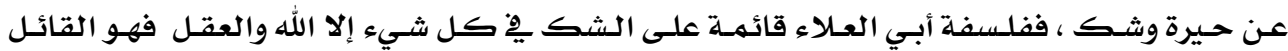
'

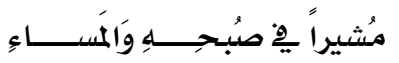

قَقصى إجـتِهادي أَنْ أَظُنََّ وَأحلِسِسا
كَذَبَ الظَنْ لا إمامَ سِيوى العَقل

وهو القائل ِِِ الشكَّ :

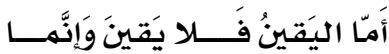

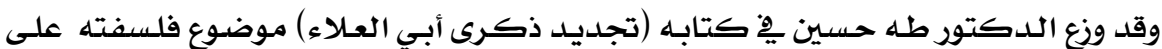

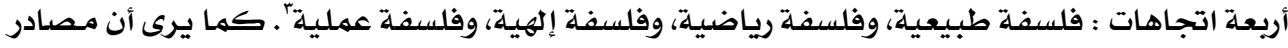

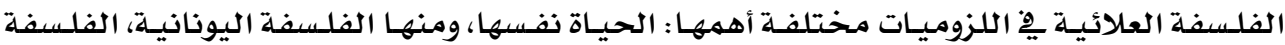

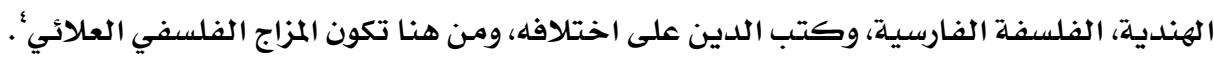

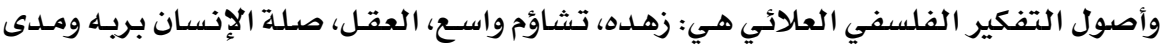

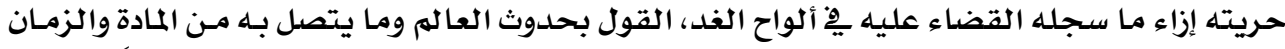

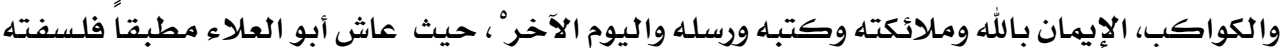

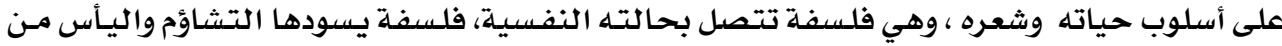

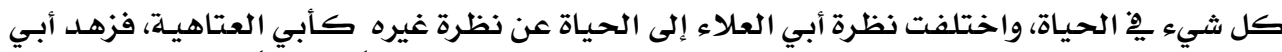

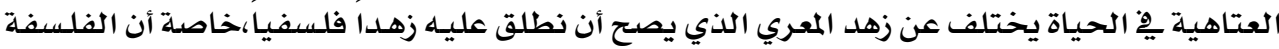

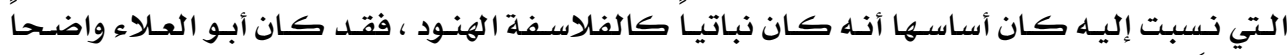

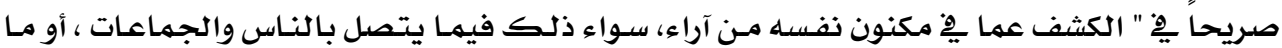

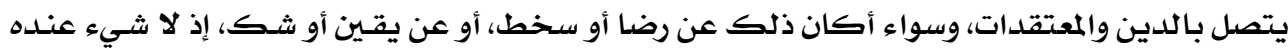

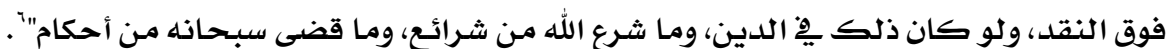

ومن خلال الأسبـاب التي أدت إلى عزلته وأصول فلسفته أرى أن أبا العلاء استطاع أن يطوع

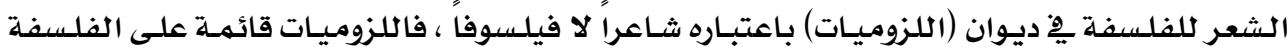

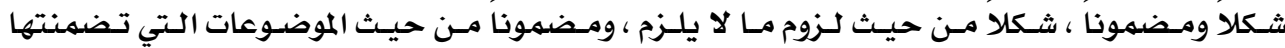

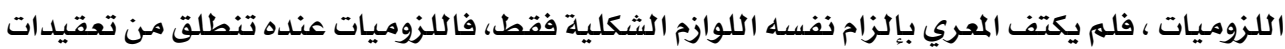

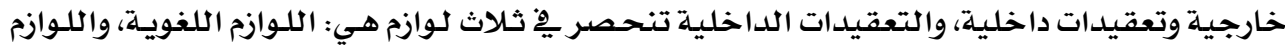

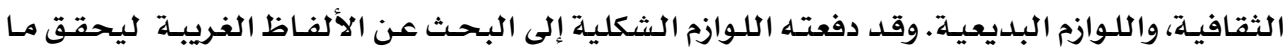

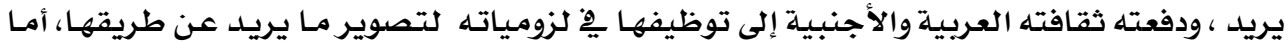

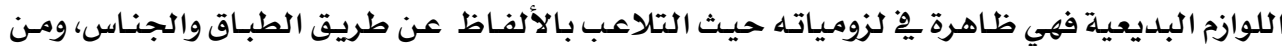




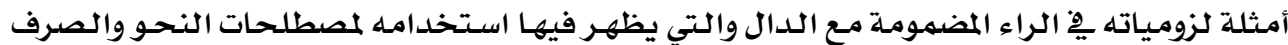
وفيها يفسر الصلة بين الأصول والفروع قوله ' :

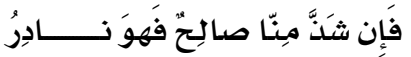

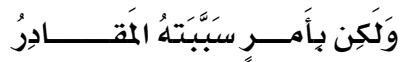

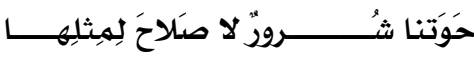

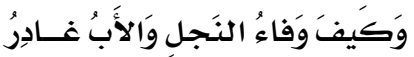

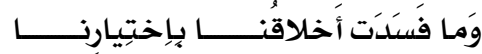

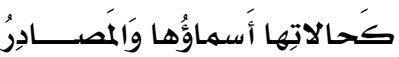

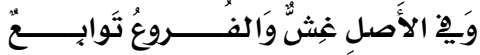

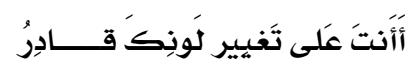

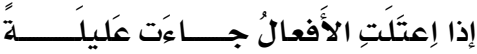

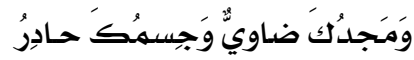

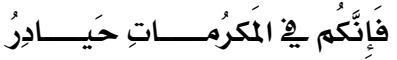
أَواني وَقَالَ الغابِ أَيْنَ الخَـــــوادِرُ

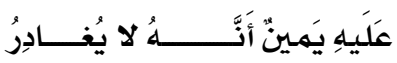

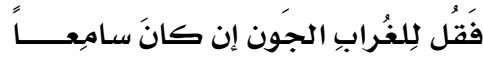

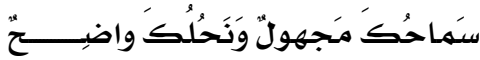
بَني العَصرَ إن كانَت طُوالاً شُخوصُكمَ

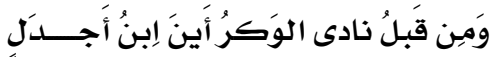

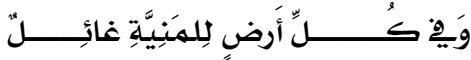
فَوادِ وتَتَردى ِِِ ذُراهـا الفَــــــوادِرُ

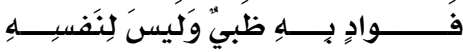

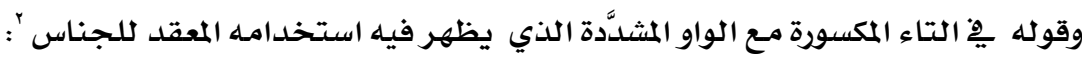

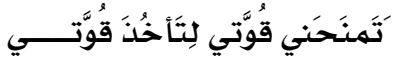

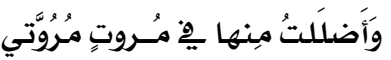

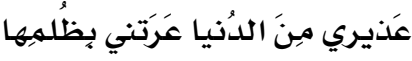

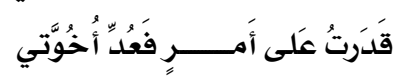

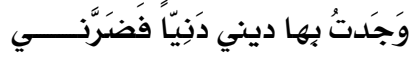

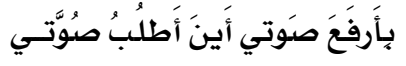

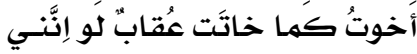
فَهما لِهَتابي لَيسَ يَغَسِلُ حُوَّتَي

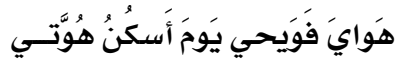

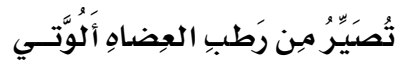

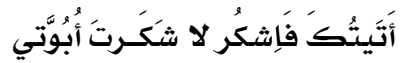

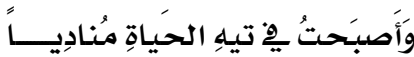
وُما زالَ حُوتي راصِِي وَهوَ آخِذيدي

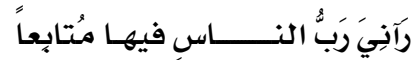

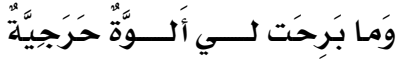

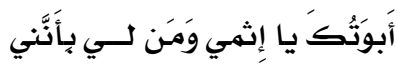
و قوله يِّ الهمـزة المكسورة مـع الميهمَّ

عليه، مثلَ حَبَاب الماءٍ ِِِ المـــــــاءِ القلبُ كالماءو، والأهــــــــــــــواءُ طافيـة فيُخْلِقِق العَهَدَ مـن هندِ وأسهــــــاءِ

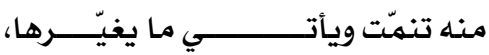
والناسُ كالدّهر، من نور وظلَهاءِ والقولُ كالخلقي، من سَيٌٍْ ومن حسَنِ،

1اللزوميات (r/ (7)

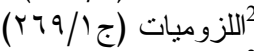
3اللزوميات ص اللزوميات (ج/ 


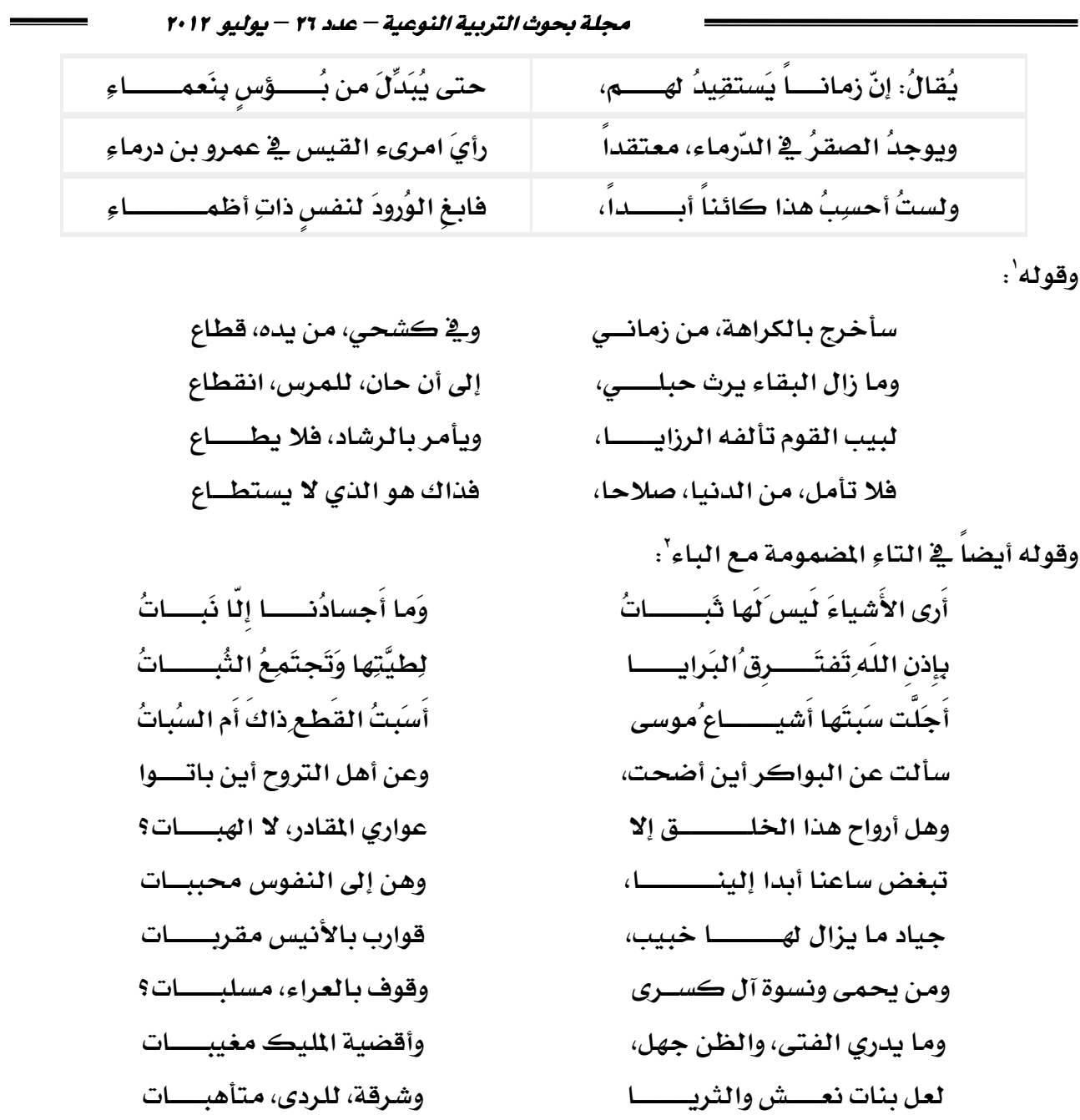

إن فلسفة أبي العـلاء، وإن له تكن فلسفة فيلسوف بمعناهـا الحقيقي، إلا أنها تعسد مححاولـة

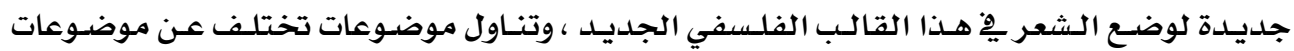

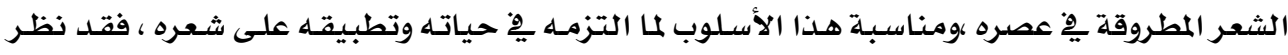

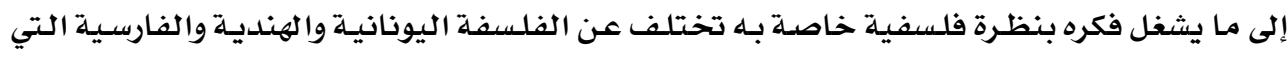

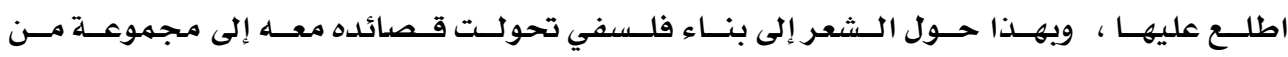
النصوص الفلسفيـة. 


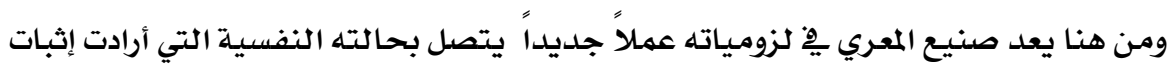

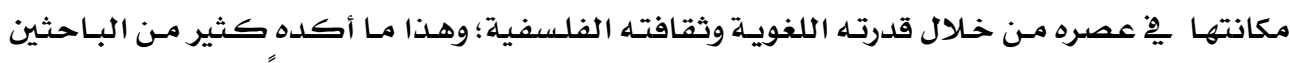

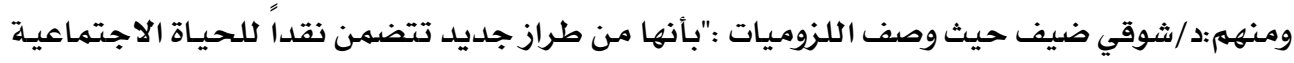

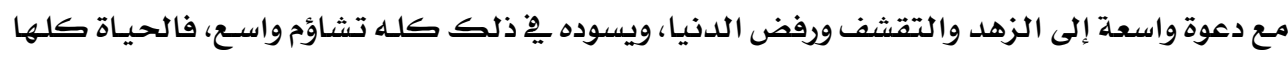

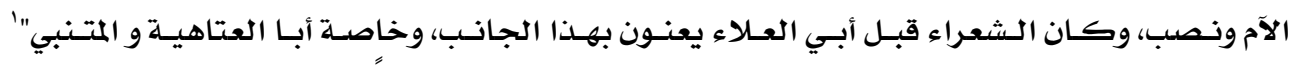

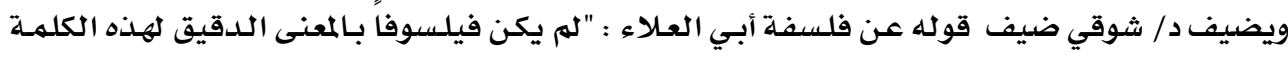

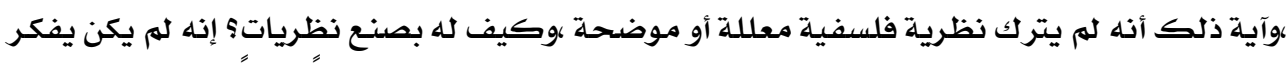

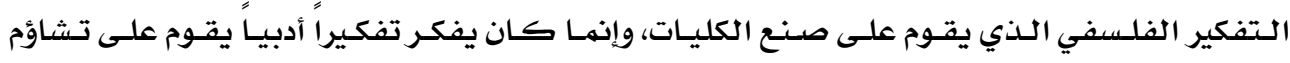

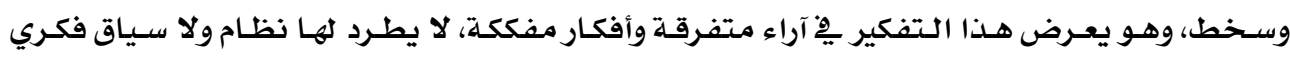

كما يرى الأب يوحنا قمير يْ كتابه ( المعري يْ لزومياته) بأن اللزوميات "فلسفة لم تقصد

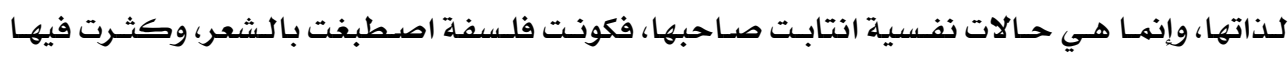

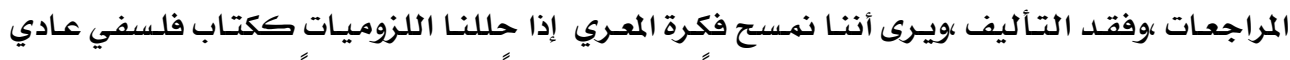

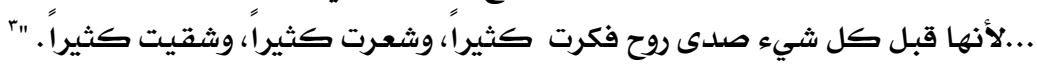

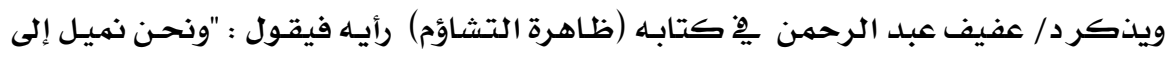

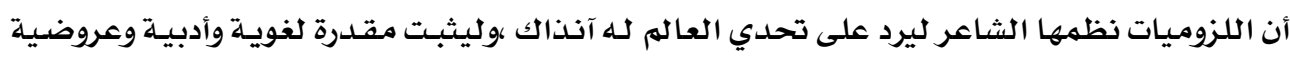

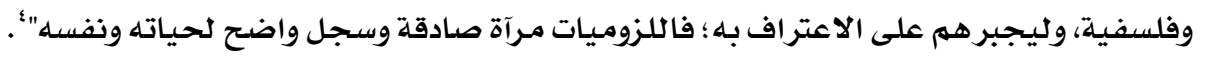

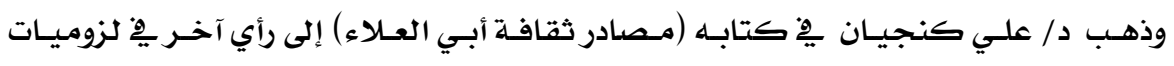

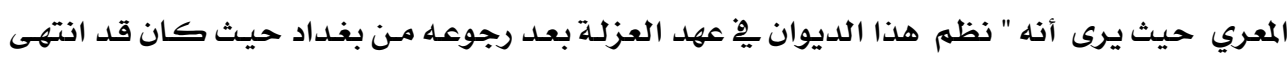

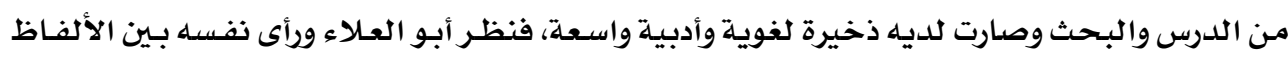

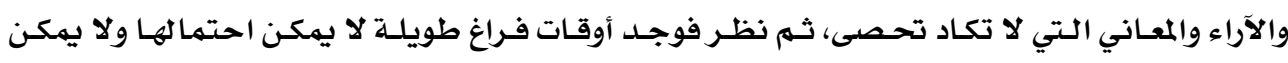

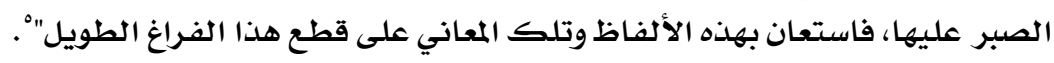

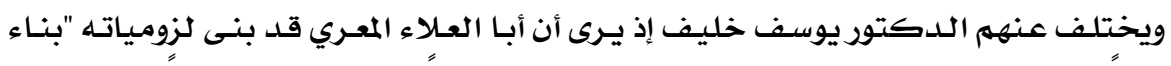

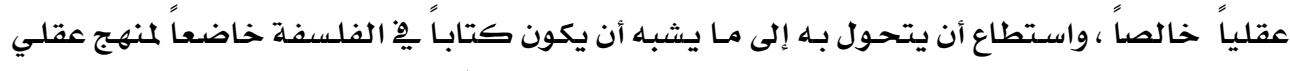

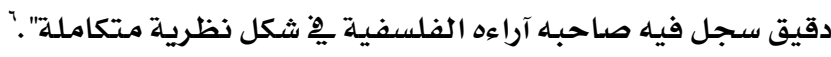

كذلك يختلف الدكتور طه حسين ِِف تفسيره للزوميات حيث يرى أن أبـا العـلاء له يرد "

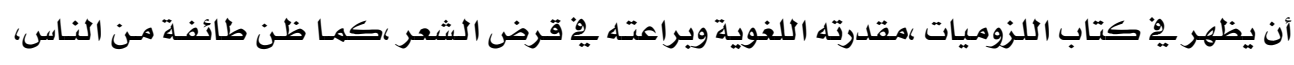

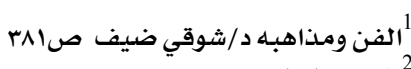

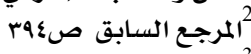

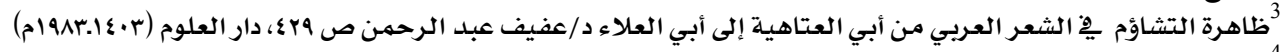
4 ${ }^{4}$

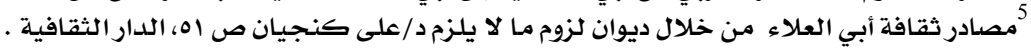

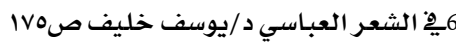




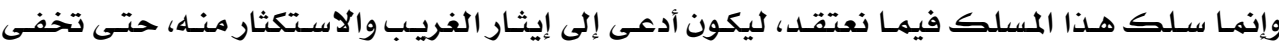

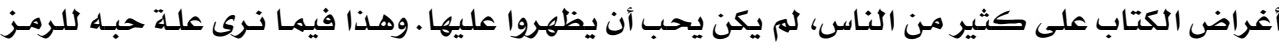

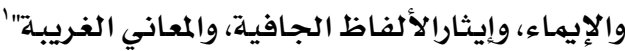
وأخيراً فقد أثرت لزوميات المعري يِّ الشعراء بعده وامتد تأثيرها إلى العصر الحسديث، وإن لهم تكن

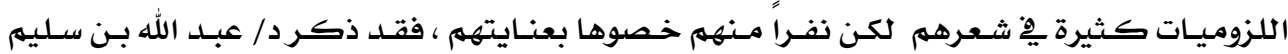

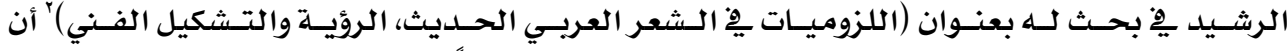

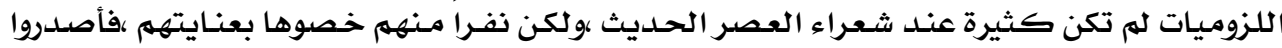

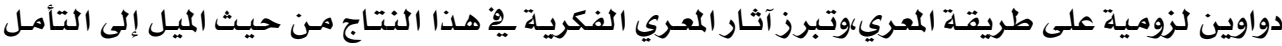

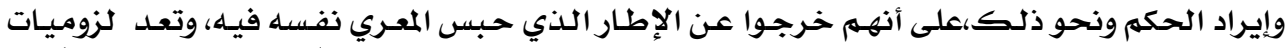

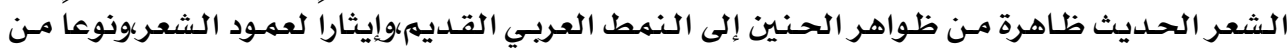

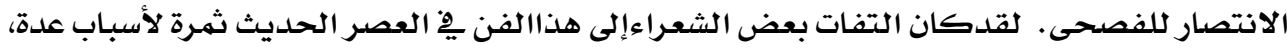

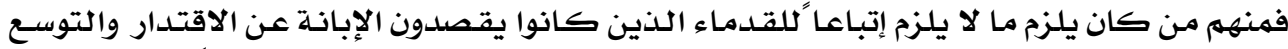

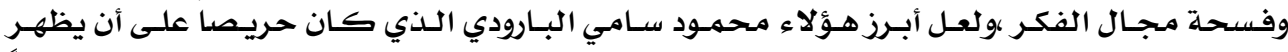

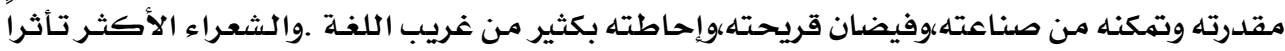

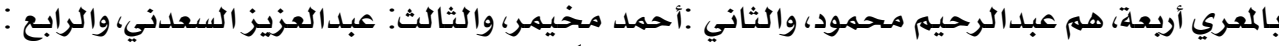

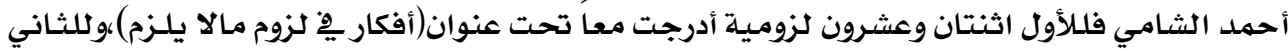

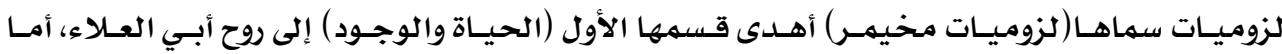

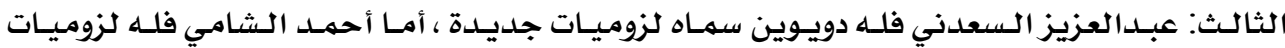
كثيرة تتبع فيها لزوميات المعري قطعة قطعـة.

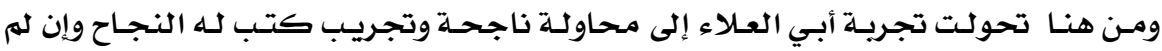

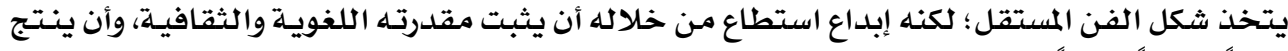

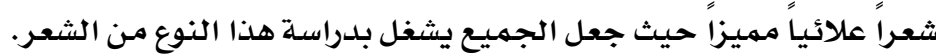

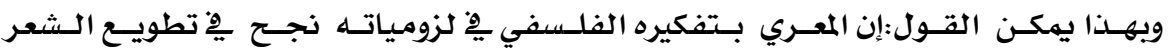

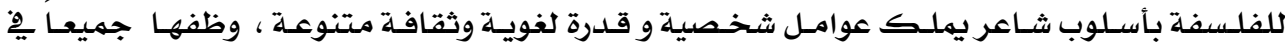

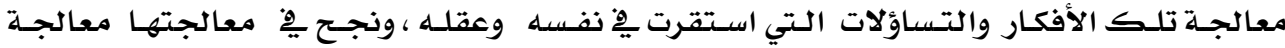

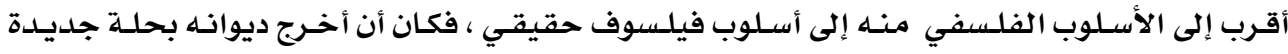

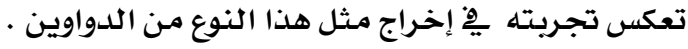
ومن أبرز الملاحظات والنتائج التي خرجنا بها من هذا البحث مـا يلي: ا. انعكـاس الحيـاة العباسـيـة الجديـدة على إنتاج الشعراء العباسـيـين، وخاصـة توظيف الشعراء

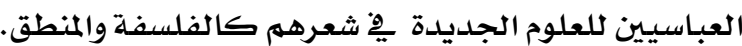




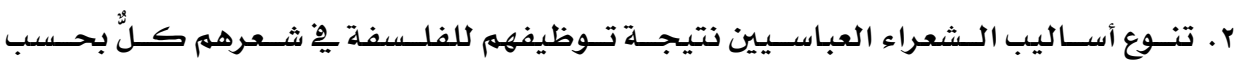
فكره وثقافته.

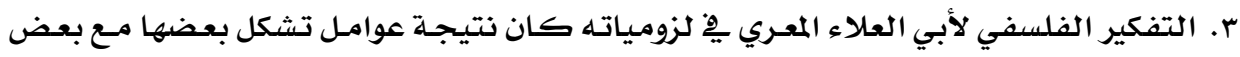

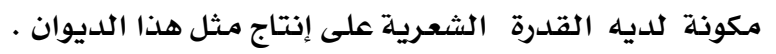

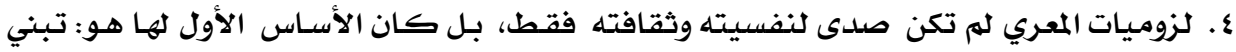

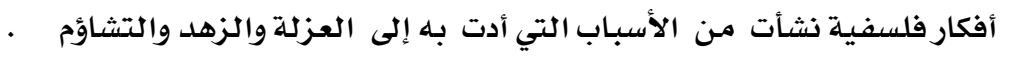

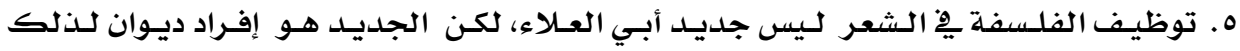

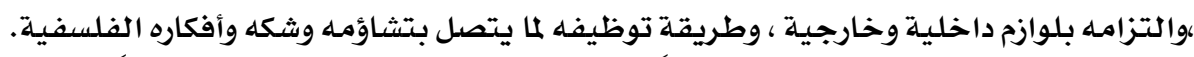

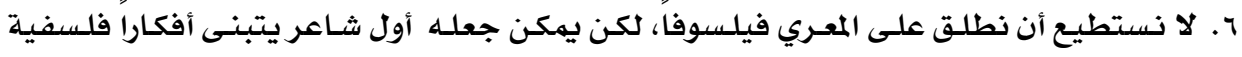

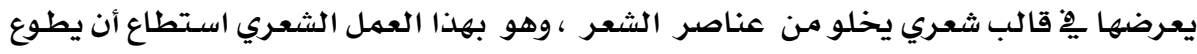

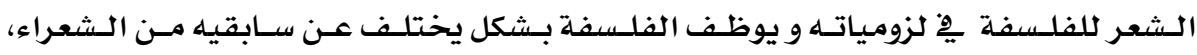

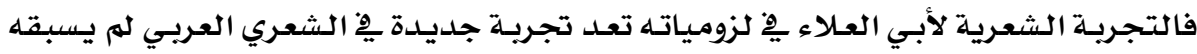

إليها أحد، وكذلك تسميلة دواوينه.

$$
\text { والله ولي التوفيق . }
$$




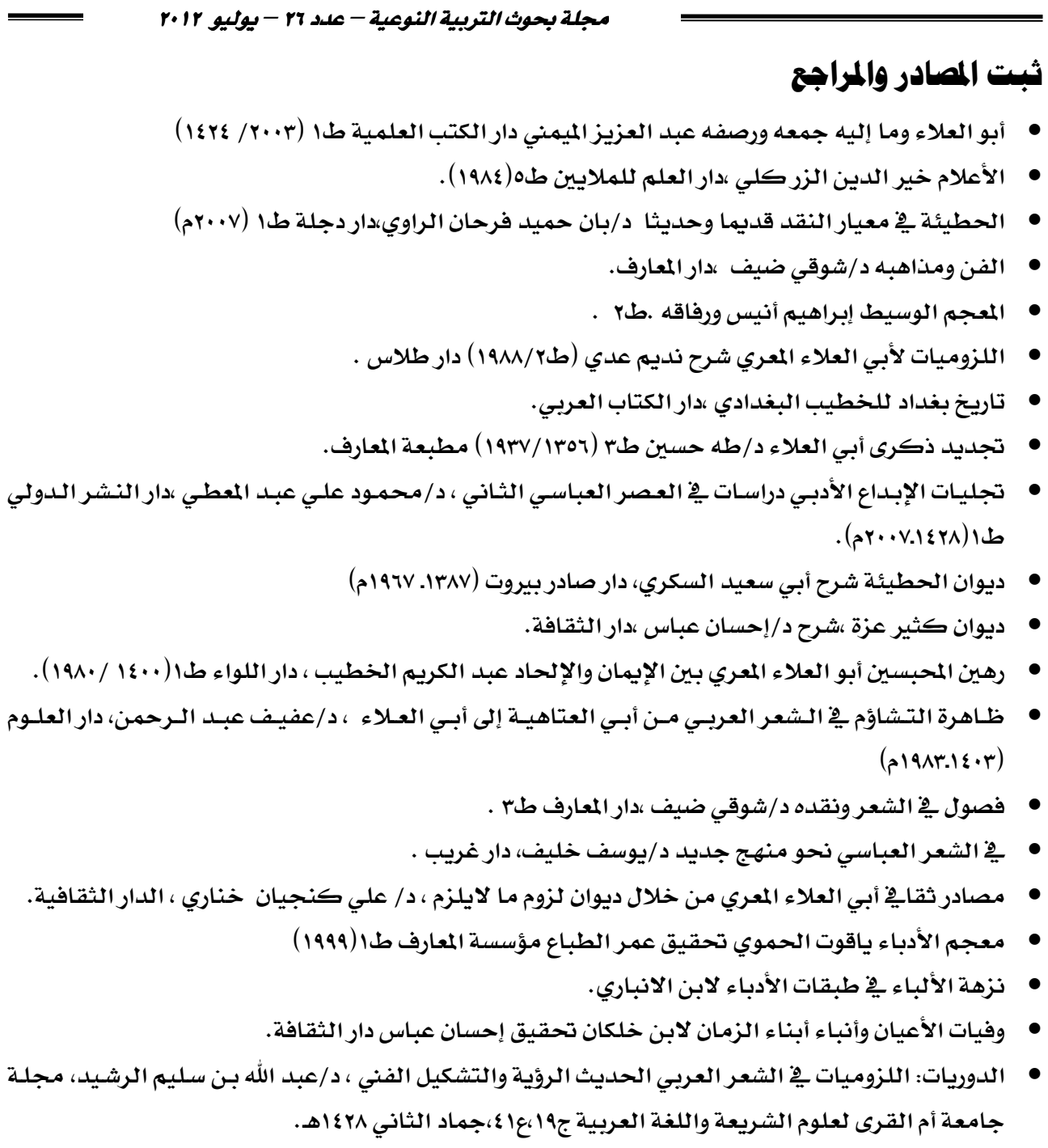

